tion "Radius of the Lost Arc", the cartoon adventures of Polymath Jones.

Quantum contains English translations from $K$ vant, a Soviet student magazine published by the Academy of Sciences of the USSR and the Academy of Pedagogical Sciences, as well as new material in English; it is devoted to mathematics and physics in roughly equal proportions. Like Mathematics Review, the magazine is full of stimulating articles written in a style aimed at the 16-20 age group, although many would be as suitable for investigative reading for UK university courses as they would for A-level courses. The mathematics articles are generally less embedded in everyday life contexts and draw skilfully on the intrinsic mathematics to engage the interest of the reader. Again, the material is of good quality and well presented. Regular features include an analysis in recreational mathematics, an update on events and current activities of interest to science students, more particularly in the United States, and a selection of nice problems, ranging from the quick "Brainteasers" to the more meaty "Challenges" and "Math Investigations".

Together with Mathematical Spectrum, which sits somewhere between the two, Mathematics Review and Quantum provide excellent mathematical reading for students at school and university. In short, everything the teacher wanted to say about maths but was afraid to spend time on.

Tony Barnard is in the Department of Mathematics, King's College London, Strand, London WC2R 2L3, UK.

\section{From the horse's mouth}

\section{Nigel Williams}

Science and Public Affairs. Editor Walter Bodmer. Royal Society. 4/yr. UK $£ 20$, elsewhere $£ 21.50, \$ 43$.

THIS is not a new product but a relaunch last year in glossy-covered 'magazine' format of a previously small-format, scholarly looking journal. It is produced by the Royal Society in conjunction with the British Association for the Advancement of Science. The journal's original aims were to foster the understanding of scientific issues by the public and to explain the implications of discoveries in science and technology for everyday life. The journal is pursuing more of a mission than a gap in the market.

These rather grand aims broadly remain in the new format, which the editor, Walter Bodmer, hopes will make the journal (now, rather selfconsciously, referred to as a magazine) "more inviting" and "easier to read for busy people". There is also more of it, with four issues promised each year.

The scope is necessarily broad, with engineering and technology (the actual 'science' that the public directly experiences) given welcome prominence alongside more basic topics such as cancer biology and cloud physics. Expertise abounds, but the quality of the writing is very uneven. Regular round-ups in areas of current interest are promised. "Embryos and ethics" has already appeared with a particularly lucid contribution from Sydney Brenner, but I think one would need to know some genetics to follow his argument fully.

The authors, mostly British, consist of a distinguished bunch of practitioners, administrators and industrialists with a scattering of lesser-knowns and journalists. If you want to know about British science policy issues, it is here that you are most likely to get a view from the horse's mouth. A new reviews section has yet to get properly under way.

Although the colourful cover could just about - front something one could find at the newsstand, has the journal really transformed itself into a magazine? It is certainly more inviting with its attractive text layout and good modern typography, but some of the illustrations - dull publicity handouts and amateurish cartoons in particular - let it down.

Busy people will still read this 'magazine', but largely, I suspect, when they see a topic or author of interest, and most of the readers will be scientists. With many of the articles in excess of 3,000 words, it still has a low browse factor, which is a pity given the readership that some of the articles, such as Fran Balkwill's splendid account of the cytokines, deserve.

But scientists and policymakers can learn a little more than their own business. An account of the development of the compact disc at Philips reveals the enormous complexity of factors and timings involving in the currently fashionable area of innovation, and challenges glib links between science and technology.

The publication will be successful as a magazine, journal or whatever on the quality and clarity of what it says and who is saying it, but not on its format. $\square$

Nigel Williams is at the Wellcome Research Institute in Science and Medicine, 5TB, UK. 179 Great Portland Street, London W1N

\section{Also submitted for review}

The following is a list of journals received that were eligible for review but which for one reason or another are not covered in the preceding pages. The list does not include journals sent in that had not published enough titles to be considered.

Antiviral Chemistry and Chemotherapy (Blackwell Scientific)

Applicable Algebra in Engineering, Communication and Computing (Springer)

Atomization and Sprays (Hemisphere)

Bio-medical Materials and Engineering (Pergamon)

Computational Mathematics and Modelling (Consultants Bureau).

Computing Systems in Engineering (Pergamon)

Designs, Codes and Cryptography (Kluwer)

Dreaming (Human Science)

Dynamics and Control (Kluwer)

European Journal of Information Systems (Operational Research Society)

Fish and Shellfish Immunology (Harcourt Brace Jovanovich)

Fresenius Environmental Bulletin (Birkhäuser)

Frontier Perspectives (Center for Frontier Sciences at Temple University) Immunology and Infectious Diseases (Rapid Communications of Oxford) International Journal of Algebra and Computation (World Scientific)

International Journal of Computational Geometry and Applications (World Scientific)

International Journal of Environmental Health Research (Chapman and Hall) International Journal of Software and Knowledge Engineering (World Scientific)

Journal of Circuits, Systems, and Computers (World Scientific)

Journal of Global Optimization (Kluwer)

Journal of Information Systems (Blackwell Scientific)

Journal of Logic and Computation (Oxford University Press)

Journal of Micromechanics and Microengineering (IOP)

Journal of the Moscow Physical Society (IOP)

Journal of Systems Integration (Kluwer)

Mathematical Models and Methods in Applied Sciences (World Scientific)

Mechatronics: Mechanics - Electronics Control (Pergamon)

Neuromuscular Disorders (Pergamon)

Optical Computing and Processing (Taylor and Francis)

Plasma Devices and Operations (Gordon and Breach)

Process Control and Quality (Elsevier)

Science, Technology and Development (Frank Cass)

Shock Waves (Springer)

Waves in Random Media (Cambridge University Press)

User Modeling and User-Adapted Interaction (Kluwer) 